OPEN ACCESS

Edited by:

Rodrigo Iturriaga,

Pontificia Universidad Católica de Chile, Chile

Reviewed by:

Beth J. Allison,

Hudson Institute of Medical Research,

Australia

Charles Christoph Roehr, University of Oxford, United Kingdom

*Correspondence:

Ovidiu Constantin Baltatu ocbaltatu@anhembi.br; ocbaltatu@gmail.com Luciana Aparecida Campos labaltatu@anhembi.br;

camposbaltatu@gmail.com

Specialty section: This article was submitted to Integrative Physiology, a section of the journal

Frontiers in Physiology

Received: 08 July 2018 Accepted: 02 October 2018 Published: 22 October 2018

Citation:

Medeiros TKS, Dobre M, da Silva DMB, Brateanu A, Baltatu OC and Campos LA (2018) Intrapartum Fetal Heart Rate: A Possible Predictor of Neonatal Acidemia and APGAR

Score. Front. Physiol. 9:1489. doi: 10.3389/fphys.2018.01489

\section{Intrapartum Fetal Heart Rate: A Possible Predictor of Neonatal Acidemia and APGAR Score}

\author{
Thâmila Kamila de Souza Medeiros ${ }^{1,2}$, Mirela Dobre ${ }^{3}$, \\ Daniela Monteiro Baptista da Silva ${ }^{1,2}$, Andrei Brateanu ${ }^{4}$, Ovidiu Constantin Baltatu,2* \\ and Luciana Aparecida Campos ${ }^{1,2 *}$
}

\footnotetext{
${ }^{1}$ Center of Innovation, Technology and Education at Anhembi Morumbi University - Laureate International Universities, São José dos Campos, Brazil, ${ }^{2}$ School of Health Sciences at Anhembi Morumbi University - Laureate International Universities, São José dos Campos, Brazil, ${ }^{3}$ Division of Nephrology and Hypertension, University Hospitals, Cleveland, OH, United States, ${ }^{4}$ Medicine Institute, Cleveland Clinic, Cleveland, $\mathrm{OH}$, United States
}

Background: Predicting perinatal outcomes based on patterns of fetal heart rate (FHR) remains a challenge. The aim of this study was to evaluate intrapartum FHR variability as predictor for neonatal acidemia and APGAR score.

Methods: This was a retrospective observational study of 552 childbirths. Multivariable linear regression models were used to assess the association between FHR variability and each of the following outcomes: arterial cord blood $\mathrm{pH}$ and base deficit, Apgar 1 , and 5 scores. Variables used for adjustment were maternal age, comorbidities (gestational diabetes, preeclampsia, maternal fever, and hypertension), parity, gravidity, uterine contractions, and newborn gestational age, and weight at birth.

Results: The following factors were associated with an increased risk of metabolic acidosis and low Apgar scores at birth: increased mean and coefficient of variation (CV) of the FHR, type of delivery and decreased parity. Each 10-beat/min increase in the FHR was associated with an increase of $0.43 \mathrm{mEq} / \mathrm{L}$ in the base deficit, and a decrease of 0.01 in the pH, 0.2 in the Apgar 1, and 0.14 in the Apgar 5 scores. Each 10\% increase in the $\mathrm{CV}$ of the FHR was associated with an increase of $4.05 \mathrm{mEq} / \mathrm{L}$ in the base deficit and a decrease of 0.13 in the $\mathrm{pH}, 1.31$ in the Apgar 1, and 0.86 in the Apgar 5 scores.

Conclusion: These data suggest the intrapartum FHR variability is physiologically relevant and can be used for predicting the acidemia and Apgar scores at birth of the newborn infants without severe cases of morbidity and from uncomplicated pregnancies.

Keywords: fetal monitoring, heart rate, perinatal outcome, noninvasive prenatal diagnosis, neonatal acidemia, APGAR 


\section{INTRODUCTION}

Contemporary research aims to identify reliable and early markers for the neonatal acidemia and the physical condition of a newborn infant (Devane et al., 2012, 2017). Intrapartum cardiotocography monitors fetal heart rate (FHR) and uterine contractions and is commonly used for the early detection of fetal distress (Stout and Cahill, 2011).

It is theorized that intrapartum cardiotocography FHR could detect fetal hypoxia and/or acidosis allowing a timely intervention to reduce adverse neonatal outcomes such as postnatal cerebral palsy. This is based on the theory that intrapartum hypoxia may lead to alterations in the fetal central nervous system that directly affects the electrical activity of the fetal heart and could also induce neonatal cerebral palsy (Garabedian et al., 2017). Indeed, cardiotocography FHR parameters including baseline FHR and its variability appear to be independent predictors of fetal acidosis (Silberstein et al., 2017), were associated with a substantial decrease in early neonatal mortality and morbidity (Chen et al., 2011). At present, however, there is no consensus regarding sensitivity and specificity of cardiotocography classifications in predicting acidemia, with three guidelines for cardiotocography interpretation provided by the International Federation of Gynecology and Obstetrics (FIGO), American College of Obstetrics and Gynecology (ACOG), and National Institute for Health and Care Excellence (NICE) (Bhatia et al., 2017; Santo et al., 2017).

The improvement in the accuracy of FHR pattern interpretation through a continuous FHR centralization system is envisaged to be beneficial in reducing the incidence of neonatal acidemia (Michikata et al., 2016). To improve the predictive efficacy of cardiotocography FHR, diagnostic algorithms are currently being investigated to be used in real-time computerized systems for decision support (van Scheepen et al., 2016).

In this study, we aimed at investigating whether the intrapartum baseline and variability parameters of FHR are independently associated with neonatal acidemia and the APGAR scores of the newborn infants without severe cases of morbidity and from uncomplicated pregnancies.

\section{MATERIALS AND METHODS}

\section{Study Design and Setting}

A single-center retrospective observational study of 552 childbirths at the University Hospital Brno (UHB), Czechia (Chudacek et al., 2014). The hospital records were consecutively selected to pair both clinical and cardiotocography signal parameters.

\section{Clinical Data}

Clinical selection criteria (Chudacek et al., 2014) included maternal age (maternal age $>18$ years), gravidity (only singleton, uncomplicated pregnancies), gestational week (weeks of gestation $\geq 37$ ), delivery type (the majority of the database consists of vaginal deliveries), fetuses without known congenital defects or known intrauterine growth restriction (IUGR). Additional criteria considered were: sex of the fetus, parity, and risk factors including gestational diabetes, preeclampsia, maternal fever $\left(>37.5^{\circ} \mathrm{C}\right)$, hypertension, and meconium stained fluid. The cohort included neonates without severe cases of neonatal morbidity, hypoxic ischemic encephalopathy, or seizures.

\section{Cardiotocography Data}

Cardiotocography recordings included contained time information and signal of FHR and uterine contractions sampled at $4 \mathrm{~Hz}$ were recorded starting 90 min preceding the delivery. Cardiotocography recordings selection criteria (Chudacek et al., 2014) were the signal length: 90 min preceding the delivery with 1 st stage was limited to a maximum of $60 \mathrm{~min}$ and 2 nd stage to $30 \mathrm{~min}$ in order to keep recordings easily comparable. Other criteria were: missing signal, noise and artifacts, and type of measurement device. The database is composed as a mixture of recordings acquired by ultrasound doppler probe, direct scalp measurement or combination of both, reflecting the clinical reality at the obstetrics ward. Cardiotocographies were recorded using STAN S21 and S31 (Neoventa Medical, Mölndal, Sweden) and Avalon FM40 and FM50 (Philips Healthcare, Andover, MA, United States) fetal monitors.

The cardiotocography recordings and clinical data were matched using anonymous unique identifiers generated by the hospital information system. A flowchart diagram describing the process of data selection for the final database is presented in the original publication (Chudacek et al., 2014).

The acid-base status ( $\mathrm{pH}$ and base deficit) of umbilical cord arterial blood was measured at the moment of birth to evaluate the metabolic condition of neonates.

Apgar's scores (Apgar) at 1 and 5 min after birth evaluated the outcome of the delivery based on five categories: breathing effort, heart rate, muscle tone, reflexes, and skin color.

The CARDIOTOCOGRAPHY database is available at PhysioNet $^{1}$ ((Chudacek et al., 2014). All Physionet databases have been fully anonymized and may be used without further institutional review board approval.

\section{Statistical Analysis}

The FHR variability was determined using coefficient of variation (CV), which equals the standard deviation divided by the mean (Pereira et al., 2017). The characteristics of study participants were depicted using standard descriptive statistics, overall and stratified by quartiles of the mean of FHR. Chi-square $\left(\chi^{2}\right)$ test of independence for categorical (nominal) variables and Analysis of variance (ANOVA) test for continuous variables were used to analyze the covariates of interest.

Multivariable linear regression models were used to assess the association between FHRVand each of the following outcomes: $\mathrm{pH}$, base deficit, Apgar 1, and 5 scores. Variables used for adjustment were maternal age, comorbidities, parity, gravidity,

\footnotetext{
${ }^{1}$ https://physionet.org/physiobank/database/ctu-uhb-ctgdb/
} 
uterine contractions, and newborn gestational age, and weight at birth.

All statistical tests were two sided, and $P<0.05$ was considered significant. IBM Corp (2016) SPSS Statistics for MAC, Version 24.0, was used for analyses.

\section{RESULTS}

\section{Patient Characteristics}

A total of 552 study participants were included in the study. The age of the mothers was 30 (27-33) median (IQR) years and gestational age was 40 (39-41) median (IQR) weeks. Characteristics of study participants distributed according to quartiles of the mean of FHR are summarized in Table 1. Patients in the lowest vs. highest quartile of the mean of FHR had a higher CV of the FHR $(14.73 \pm 3.56$ vs. $11.24 \pm 3.85)$. Mean of FHR was not associated with maternal age, history of diabetes mellitus or hypertension or preeclampsia, delivery type, gravidity, parity, gestational week, and mean of uterine contractions.

\section{Association Between FHR and Metabolic Acidosis}

The median $\mathrm{pH}$ values of the cohort were 7.25 (IQR: 7.177.3) [min to max: 6.85-7.47]. In multivariable adjusted models, the following factors were associated with an increased risk of metabolic acidosis at birth: increased mean and CV of the FHR, type of delivery (Caesarian section over vaginal), decreased parity (Tables 2, 3). The following parameters were not associated with risk of metabolic acidosis at birth: maternal age, history of diabetes mellitus, hypertension, preeclampsia, gravidity, gestational week, uterine contractions, newborn sex or weight.

Each 10-beat/min increase in the FHR was associated with a 0.01 decrease in the $\mathrm{pH}$ and a $0.43 \mathrm{mEq} / \mathrm{L}$ increase in the base deficit.

Each $10 \%$ increase in the $\mathrm{CV}$ of the FHR was associated with a 0.13 decrease in the $\mathrm{pH}$ and a $4.05 \mathrm{mEq} / \mathrm{L}$ increase in the base deficit.

\section{Association Between FHR and Apgar Scores}

In multivariable adjusted models, the following factors were associated with an increased risk of low Apgar scores at birth: increased mean and $\mathrm{CV}$ of the FHR, history of preeclampsia, type of delivery (Caesarian section over vaginal), decreased parity (Tables 4, 5). The following parameters were not associated with risk of low Apgar scores at birth: maternal age, history of diabetes mellitus, hypertension, gravidity, uterine contractions, newborn sex or weight.

TABLE 1 | Characteristics of study participants by quartile of mean fetal heart rate.

\begin{tabular}{|c|c|c|c|c|c|c|c|}
\hline \multicolumn{2}{|l|}{ Characteristics } & $\begin{array}{l}\text { All participants } \\
\qquad \begin{array}{c}N=552 \\
N(\%) \text { or } \\
\text { Mean } \pm \text { SD }\end{array}\end{array}$ & \multicolumn{4}{|c|}{ Quartiles of the mean fetal heart rate (FHR) } & $P$-value \\
\hline \multicolumn{8}{|l|}{ Maternal } \\
\hline Age (years) & & $29.60 \pm 4.72$ & $30.22 \pm 4.63$ & $29.48 \pm 4.47$ & $29.15 \pm 5.11$ & $29.54 \pm 4.64$ & 0.29 \\
\hline \multirow[t]{2}{*}{ History of hypertension } & No & $508(92)$ & $125(90.6)$ & $127(92)$ & $127(92)$ & $129(93.5)$ & 0.85 \\
\hline & Yes & $44(8)$ & $13(9.4)$ & $11(8)$ & $11(8)$ & $9(6.5)$ & \\
\hline \multirow[t]{2}{*}{ History of Preeclampsia } & No & $535(96.9)$ & $131(94.9)$ & $134(97.1)$ & $134(97.1)$ & $136(98.6)$ & 0.38 \\
\hline & Yes & $17(3.1)$ & $7(5.1)$ & $4(2.9)$ & $4(2.9)$ & $2(1.4)$ & \\
\hline Delivery type & 1 & $506(91.7)$ & $127(92)$ & $132(95.7)$ & $127(92)$ & $120(87)$ & 0.07 \\
\hline \multicolumn{2}{|l|}{ Gestational week } & $39.94 \pm 1.71$ & $40.04 \pm 1.11$ & $39.81 \pm 2.78$ & $40.02 \pm 1.20$ & $39.88 \pm 1.13$ & 0.63 \\
\hline \multicolumn{2}{|c|}{ UC - mean (contractions/min) } & $24.82 \pm 10.54$ & $24.45 \pm 11.48$ & $24.16 \pm 10.46$ & $25.54 \pm 10.12$ & $25.14 \pm 10.08$ & 0.69 \\
\hline \multicolumn{2}{|c|}{$\mathrm{UC}-\mathrm{CV}$} & $75.48 \pm 25.70$ & $74.90 \pm 28.15$ & $73.76 \pm 27.29$ & $80.70 \pm 25.06$ & $72.61 \pm 21.29$ & 0.04 \\
\hline \multicolumn{8}{|l|}{ Newborn } \\
\hline \multicolumn{2}{|l|}{ FHR - mean (beats/min) } & $134,90 \pm 11.73$ & $120.85 \pm 4.87$ & $130.40 \pm 2.33$ & $138.02 \pm 2.23$ & $150.31 \pm 7.19$ & $<0.001$ \\
\hline \multicolumn{2}{|l|}{$\mathrm{FHR}-\mathrm{CV}$} & $12.86 \pm 3.91$ & $14.73 \pm 3.56$ & $12.88 \pm 3.66$ & $12.55 \pm 3.77$ & $11.24 \pm 3.85$ & $<0.001$ \\
\hline \multirow[t]{2}{*}{ Sex } & Female & $286(51.8)$ & $76(55.1)$ & $70(50.7)$ & $63(45.7)$ & $77(55.8)$ & 0.30 \\
\hline & Male & $266(48.2)$ & $62(44.9)$ & 68 (49.3) & $75(54.3)$ & $61(44.2)$ & \\
\hline \multicolumn{2}{|l|}{ Newborn weight (g) } & $3397.52 \pm 459.58$ & $3321.12 \pm 442.09$ & $3401.28 \pm 472.53$ & $3431.88 \pm 447.37$ & $3435.80 \pm 471.34$ & 0.13 \\
\hline
\end{tabular}

UC, uterine contractions; FHR, fetal heart rate; $C V$, coefficient of variation. 
Each 10-beat/min increase in the FHR was associated with a 0.2 and 0.14 decrease in the Apgar score at 1 and 5 min after birth, respectively.

TABLE 2 | Association between maternal and newborn parameters and pH.

$\mathrm{pH}$

\begin{tabular}{|c|c|c|c|c|}
\hline \multirow[t]{2}{*}{ Parameters } & \multirow{2}{*}{$\begin{array}{l}\text { Unstandardized } \\
\text { B Coefficients }\end{array}$} & \multicolumn{2}{|c|}{ 95\% Confidence interval } & \multirow[t]{2}{*}{$P$-value } \\
\hline & & $\begin{array}{l}\text { Lower } \\
\text { bound }\end{array}$ & $\begin{array}{l}\text { Upper } \\
\text { bound }\end{array}$ & \\
\hline Maternal age & 0.000 & -0.003 & 0.002 & 0.70 \\
\hline $\begin{array}{l}\text { History of diabetes } \\
\text { mellitus }\end{array}$ & -0.009 & -0.049 & 0.030 & 0.64 \\
\hline $\begin{array}{l}\text { History of } \\
\text { hypertension }\end{array}$ & -0.033 & -0.069 & 0.004 & 0.08 \\
\hline $\begin{array}{l}\text { History of } \\
\text { preeclampsia }\end{array}$ & -0.005 & -0.059 & 0.049 & 0.85 \\
\hline Delivery type & -0.042 & -0.072 & -0.013 & 0.005 \\
\hline Gravidity & -0.003 & -0.015 & 0.010 & 0.67 \\
\hline Parity & 0.036 & 0.019 & 0.053 & $<0.001$ \\
\hline Gestational week & 0.006 & -0.004 & 0.015 & 0.25 \\
\hline $\begin{array}{l}\text { UC - mean } \\
\text { (contractions/min) }\end{array}$ & $-5.328 E-5$ & -0.001 & 0.001 & 0.91 \\
\hline $\mathrm{UC}-\mathrm{CV}$ & 0.000 & -0.001 & 0.000 & 0.32 \\
\hline $\begin{array}{l}\text { FHR - mean } \\
\text { (beats/min) }\end{array}$ & -0.001 & -0.002 & -0.001 & 0.001 \\
\hline $\mathrm{FHR}-\mathrm{CV}$ & -0.013 & -0.015 & -0.010 & $<0.001$ \\
\hline Newborn sex & -0.013 & -0.033 & 0.007 & 0.19 \\
\hline Newborn weight (g) & $-1.108 E-5$ & 0.000 & 0.000 & 0.34 \\
\hline
\end{tabular}

TABLE 3 | Association between maternal and newborn parameters and base deficit.

\section{Base deficit (mEq/L)}

\begin{tabular}{|c|c|c|c|c|}
\hline \multirow[t]{2}{*}{ Parameters } & \multirow{2}{*}{$\begin{array}{l}\text { Unstandardized } \\
\text { B Coefficients }\end{array}$} & \multicolumn{2}{|c|}{ 95\% Confidence interval } & \multirow[t]{2}{*}{$P$-value } \\
\hline & & $\begin{array}{l}\text { Lower } \\
\text { bound }\end{array}$ & $\begin{array}{l}\text { Upper } \\
\text { bound }\end{array}$ & \\
\hline Maternal age & 0.052 & -0.010 & 0.115 & 0.10 \\
\hline $\begin{array}{l}\text { History of diabetes } \\
\text { mellitus }\end{array}$ & 0.709 & -0.338 & 1.756 & 0.18 \\
\hline $\begin{array}{l}\text { History of } \\
\text { hypertension }\end{array}$ & 0.185 & -0.763 & 1.132 & 0.70 \\
\hline $\begin{array}{l}\text { History of } \\
\text { Preeclampsia }\end{array}$ & -0.244 & -1.743 & 1.254 & 0.75 \\
\hline Delivery type & 1.970 & 1.001 & 2.939 & $<0.001$ \\
\hline Gravidity & 0.090 & -0.210 & 0.391 & 0.55 \\
\hline Parity & -1.188 & -1.635 & -0.740 & $<0.001$ \\
\hline Gestational week & 0.016 & -0.139 & 0.171 & 0.84 \\
\hline UC - mean & -0.001 & -0.026 & 0.025 & 0.96 \\
\hline$U C-C V$ & -0.001 & -0.011 & 0.010 & 0.90 \\
\hline FHR - mean & 0.043 & 0.019 & 0.067 & $<0.001$ \\
\hline $\mathrm{FHR}-\mathrm{CV}$ & 0.405 & 0.334 & 0.476 & $<0.001$ \\
\hline Newborn sex & 0.089 & -0.439 & 0.617 & 0.74 \\
\hline Newborn weight (g) & 0.000 & 0.000 & 0.001 & 0.54 \\
\hline
\end{tabular}

Each $10 \%$ increase in the CV of the FHR was associated with a 1.31 and 0.86 decrease in the Apgar score at 1 and 5 min after birth, respectively.

TABLE 4 | Association between maternal and newborn parameters and Apgar 1 score (1 min after birth).

\section{Apgar 1 score}

\begin{tabular}{|c|c|c|c|c|}
\hline \multirow[t]{2}{*}{ Parameters } & \multirow{2}{*}{$\begin{array}{l}\text { Unstandardized } \\
\text { B Coefficients }\end{array}$} & \multicolumn{2}{|c|}{ 95\% Confidence interval } & \multirow[t]{2}{*}{$P$-value } \\
\hline & & $\begin{array}{l}\text { Lower } \\
\text { bound }\end{array}$ & $\begin{array}{l}\text { Upper } \\
\text { bound }\end{array}$ & \\
\hline Maternal age & -0.001 & -0.031 & 0.029 & 0.94 \\
\hline $\begin{array}{l}\text { History of diabetes } \\
\text { mellitus }\end{array}$ & 0.279 & -0.247 & 0.805 & 0.30 \\
\hline $\begin{array}{l}\text { History of } \\
\text { hypertension }\end{array}$ & -0.279 & -0.755 & 0.198 & 0.25 \\
\hline $\begin{array}{l}\text { History of } \\
\text { Preeclampsia }\end{array}$ & -0.767 & -1.521 & -0.014 & 0.05 \\
\hline Delivery type & -0.207 & -0.678 & 0.264 & 0.39 \\
\hline Gravidity & -0.031 & -0.181 & 0.120 & 0.69 \\
\hline Parity & 0.367 & 0.144 & 0.589 & 0.001 \\
\hline Gestational week & 0.165 & 0.087 & 0.242 & $<0.001$ \\
\hline UC - mean & 0.000 & -0.013 & 0.012 & 0.95 \\
\hline $\mathrm{UC}-\mathrm{CV}$ & -0.002 & -0.007 & 0.003 & 0.44 \\
\hline $\mathrm{FHR}$ - mean & -0.020 & -0.031 & -0.008 & 0.001 \\
\hline , FHR - CV & -0.131 & -0.166 & -0.095 & $<0.001$ \\
\hline Newborn sex & 0.208 & -0.056 & 0.471 & 0.12 \\
\hline Newborn weight (g) & -0.001 & -0.001 & 0.000 & $<0.001$ \\
\hline
\end{tabular}

TABLE 5 | Association between maternal and newborn parameters and Apgar 5 score (5 min after birth).

\begin{tabular}{|c|c|c|c|c|}
\hline \multicolumn{5}{|c|}{ Apgar 5 score } \\
\hline \multirow[t]{2}{*}{ Parameters } & \multirow{2}{*}{$\begin{array}{l}\text { Unstandardized } \\
\text { B Coefficients }\end{array}$} & \multicolumn{2}{|c|}{$95 \%$ Confidence interval } & \multirow[t]{2}{*}{$P$-value } \\
\hline & & $\begin{array}{l}\text { Lower } \\
\text { bound }\end{array}$ & $\begin{array}{l}\text { Upper } \\
\text { bound }\end{array}$ & \\
\hline Maternal age & -0.007 & -0.028 & 0.015 & 0.54 \\
\hline $\begin{array}{l}\text { History of diabetes } \\
\text { mellitus }\end{array}$ & 0.001 & -0.374 & 0.376 & 0.99 \\
\hline $\begin{array}{l}\text { History of } \\
\text { hypertension }\end{array}$ & -0.126 & -0.465 & 0.214 & 0.47 \\
\hline $\begin{array}{l}\text { History of } \\
\text { Preeclampsia }\end{array}$ & -0.938 & -1.475 & -0.400 & 0.001 \\
\hline Delivery type & -0.083 & -0.419 & 0.253 & 0.63 \\
\hline Gravidity & -0.070 & -0.177 & 0.038 & 0.20 \\
\hline Parity & 0.234 & 0.076 & 0.393 & 0.004 \\
\hline Gestational week & 0.053 & -0.002 & 0.109 & 0.06 \\
\hline UC - mean & 0.002 & -0.007 & 0.011 & 0.63 \\
\hline UC - CV & 0.000 & -0.004 & 0.003 & 0.89 \\
\hline FHR - mean & -0.014 & -0.023 & -0.006 & 0.001 \\
\hline $\mathrm{FHR}-\mathrm{CV}$ & -0.086 & -0.111 & -0.061 & $<0.001$ \\
\hline Newborn sex & 0.060 & -0.128 & 0.248 & 0.53 \\
\hline Newborn weight (g) & 0.000 & -0.001 & 0.000 & 0.003 \\
\hline
\end{tabular}




\section{DISCUSSION}

The main findings of this study are that in a cohort of uncomplicated childbirths without severe cases of neonatal morbidity, hypoxic ischemic encephalopathy, or seizures: (1) increased mean and CV of the intrapartum FHR were associated with increased risk of metabolic acidosis and low Apgar scores at birth; (2) FHR was not associated with maternal age, history of diabetes mellitus or hypertension or preeclampsia, delivery type, gravidity, parity, gestational week, mean of uterine contractions. Besides the intrapartum cardiotocography FHR, delivery type, and decreased parity were also associated with neonatal acidemia and the physical condition of a newborn infant.

Intrapartum fetal hypoxia represents an important cause of postnatal cerebral palsy or other neurologic outcomes and in a significant proportion of cases there is evidence of suboptimal care related to fetal surveillance. Umbilical artery metabolic acidosis is commonly used to detect neurological injury (Ross and Gala, 2002).

A three-tiered FHR interpretation system for intrapartum cardiotocography FHR tracing interpretation was proposed (Macones et al., 2008; American College of Obestetricians and Gynecologists, 2009). As our study did not include complicated pregnancies, it supports using the normal cardiotocography FHR (category I), which has a predictive value of $99.7 \%$ of an Apgar score more than 7 (Macones et al., 2008; Crovetto et al., 2017; Raghuraman and Cahill, 2017).

Using multivariable models to control confounders, cardiotocography FHR was recently found to be an independent predictor of fetal acidosis (Silberstein et al., 2017), respiratory morbidity in term neonates (Liu et al., 2015), and indicator for preterm cesarean delivery for increased risk of neonatal and childhood morbidity (Mendez-Figueroa et al., 2015). In our multivariable model analysis, metabolic acidosis at birth had an independent relationship with the cardiotocography FHR mean and variability and also with the type of delivery (Caesarian section over vaginal) and parity. Our results are in agreement with the study of Heinonen et al. who also found that parity, but not maternal age, was an independent risk factor for neonatal acidosis (Heinonen and Saarikoski, 2001). Corroborating our results with another study of women with a singleton term pregnancy that found previous cesarean delivery and nulliparity as risk factors for neonatal metabolic acidosis (Westerhuis et al., 2012) may indicate that not only previous but also the current cesarean delivery may represent an actual challenge to the fetus. In two studies of poor neonatal adaptation at birth with severe neonatal acidosis (umbilical artery $\mathrm{pH}$ less than 7.10) independent risk factors included abnormal cardiotocography FHR, maternal age 35 years or older, parity, prior neonatal death or cesarean delivery (Maisonneuve et al., 2011; Crovetto et al., 2017). Our data extends a valuable role for cardiotocography FHR in predicting neonatal acidosis in deliveries with Apgar 5 ranging from fairly low to normal without neurological complications.

Heart rate variability (HRV) analysis with search for new algorithms is commonly employed to measure alterations in autonomic tone with predictive value in diseases (Campos et al., 2013). We have identified the CV of the heart rate as a sensitive measure of autonomic dysfunction (Miyabara et al., 2017) and independently associated with vascular atherosclerosis (Pereira et al., 2017). In this study, we found that CV of intrapartum cardiotocography FHR is an independent predictor of neonatal acidemia and Apgar scores.

\section{Limitations and Strengths of the Study}

There are important limitations associated with this study. First, since this was a retrospective study, we could only investigate factors that were available to us in the current dataset, midto-long term outcomes of the infants being not recorded in the database. Also, fetal sleep state was not considered in this study. Second, although robust statistical methods were used to account for differences between groups, the potential for residual confounding cannot be ruled out. This study, as with most retrospective studies, is susceptible to bias. Third, the results of the study cannot be generalizable to all patients, for instance to those with an APGAR score critically low or associated with neurological complications and did not include data from neonates with severe cases of neonatal morbidity, hypoxic ischemic encephalopathy, or seizures. Limitations notwithstanding there are key strengths to this paper. To our knowledge, this is the first study with a relatively large sample size providing sufficient statistical power to explore the relationship between intrapartum FHRV and neonatal acidemia or APGAR score. Also, we adjusted for several confounders including important comorbidities.

\section{CONCLUSION}

In conclusion, the present findings provide evidence that intrapartum cardiotocography FHR could be a predictor for neonatal acidemia and the physical condition of a newborn infant, as determined by arterial cord blood $\mathrm{pH}$ and base deficit, Apgar 1, and 5 scores. Further studies are warranted to examine the potential relationship between intrapartum FHR and neonatal pathologies including neurological complications.

\section{AUTHOR CONTRIBUTIONS}

$\mathrm{OB}, \mathrm{LC}, \mathrm{AB}, \mathrm{MD}$, TM, and DdS conceived and designed the study, and analyzed and interpreted the data. $\mathrm{OB}, \mathrm{LC}, \mathrm{MD}$, and $\mathrm{AB}$ drafted the manuscript. TM, MD, DdS, AB, LC, and OB critically revised the manuscript. $\mathrm{LC}$ and $\mathrm{OB}$ are the guarantors of this work and, as such, had full access to all the data in the study and takes responsibility for the integrity of the data and the accuracy of the data analysis.

\section{FUNDING}

This research was supported by São Paulo Research Foundation to LC (FAPESP 17/11976-0). 


\section{ACKNOWLEDGMENTS}

We gratefully acknowledge Prof. Dr. Václav Chudáèek and colleagues for making available the cardiotocography database to

\section{REFERENCES}

American College of Obestetricians and Gynecologists (2009). ACOG Practice Bulletin No. 106: intrapartum fetal heart rate monitoring: nomenclature, interpretation, and general management principles. Obstet. Gynecol. 114, 192202. doi: 10.1097/AOG.0b013e3181aef106

Bhatia, M., Mahtani, K. R., Nunan, D., and Reddy, A. (2017). A cross-sectional comparison of three guidelines for intrapartum cardiotocography. Int. J. Gynaecol. Obstet. 138, 89-93. doi: 10.1002/ijgo.12161

Campos, L. A., Pereira, V. L. Jr., Muralikrishna, A., Albarwani, S., Brás, S., and Gouveia, S. (2013). Mathematical biomarkers for the autonomic regulation of cardiovascular system. Front. Physiol. 4:279. doi: 10.3389/fphys.2013.00279

Chen, H. Y., Chauhan, S. P., Ananth, C. V., Vintzileos, A. M., and Abuhamad, A. Z. (2011). Electronic fetal heart rate monitoring and its relationship to neonatal and infant mortality in the United States. Am. J. Obstet. Gynecol. 204, 491.e1-491.e10. doi: 10.1016/j.ajog.2011.04.024

Chudacek, V., Spilka, J., Bursa, M., Janku, P., Hruban, L., Huptych, M., et al. (2014). Open access intrapartum CTG database. BMC Pregnancy Childbirth 14:16. doi: 10.1186/1471-2393-14-16

Crovetto, F., Fumagalli, M., De Carli, A., Baffero, G. M., Nozza, S., Dessimone, F., et al. (2017). Obstetric risk factors for poor neonatal adaptation at birth. J. Matern. Fetal Neonatal Med. 31, 2429-2435. doi: 10.1080/14767058.2017. 1344635

Devane, D., Lalor, J. G., Daly, S., Mcguire, W., Cuthbert, A., and Smith, V. (2017). Cardiotocography versus intermittent auscultation of fetal heart on admission to labour ward for assessment of fetal wellbeing. Cochrane Database Syst. Rev. 1:CD005122. doi: 10.1002/14651858.CD005122.pub5

Devane, D., Lalor, J. G., Daly, S., Mcguire, W., and Smith, V. (2012). Cardiotocography versus intermittent auscultation of fetal heart on admission to labour ward for assessment of fetal wellbeing. Cochrane Database Syst. Rev. $2,1-39$.

Garabedian, C., De Jonckheere, J., Butruille, L., Deruelle, P., Storme, L., and Houfflin-Debarge, V. (2017). Understanding fetal physiology and second line monitoring during labor. J. Gynecol. Obstet. Hum. Reprod. 46, 113-117. doi: 10.1016/j.jogoh.2016.11.005

Heinonen, S., and Saarikoski, S. (2001). Reproductive risk factors of fetal asphyxia at delivery: a population based analysis. J. Clin. Epidemiol. 54, 407-410. doi: 10.1016/S0895-4356(00)00329-2

Liu, L., Tuuli, M. G., Roehl, K. A., Odibo, A. O., Macones, G. A., and Cahill, A. G. (2015). Electronic fetal monitoring patterns associated with respiratory morbidity in term neonates. Am. J. Obstet. Gynecol. 213, e681-e686. doi: 10. 1016/j.ajog.2015.07.013

Macones, G. A., Hankins, G. D., Spong, C. Y., Hauth, J., and Moore, T. (2008). The 2008 National Institute of Child Health and Human Development workshop report on electronic fetal monitoring: update on definitions, interpretation, and research guidelines. Obstet. Gynecol. 112, 661-666. doi: 10.1097/AOG. ob013e3181841395

Maisonneuve, E., Audibert, F., Guilbaud, L., Lathelize, J., Jousse, M., Pierre, F., et al. (2011). Risk factors for severe neonatal acidosis. Obstet. Gynecol. 118, 818-823. doi: 10.1097/AOG.0b013e31822c9198

Mendez-Figueroa, H., Chauhan, S. P., Pedroza, C., Refuerzo, J. S., Dahlke, J. D., and Rouse, D. J. (2015). Preterm cesarean delivery for nonreassuring fetal
PhysioNet. No assistance in the preparation of this article is to be declared. We thank the reviewers for their thoughtful review of the manuscript. They raised important issues and their inputs were very helpful for improving the manuscript.

heart rate: neonatal and neurologic morbidity. Obstet. Gynecol. 125, 636-642. doi: 10.1097/AOG.0000000000000673

Michikata, K., Sameshima, H., Urabe, H., Tokunaga, S., Kodama, Y., and Ikenoue, T. (2016). The regional centralization of electronic fetal heart rate monitoring and its impact on neonatal acidemia and the cesarean birth rate. J. Pregnancy 2016:3658527. doi: 10.1155/2016/36 58527

Miyabara, R., Berg, K., Kraemer, J. F., Baltatu, O. C., Wessel, N., and Campos, L. A. (2017). Quantifying effects of pharmacological blockers of cardiac autonomous control using variability parameters. Front. Physiol. 8:10. doi: 10.3389/fphys. 2017.00010

Pereira, V. L. Jr., Dobre, M., Dos Santos, S. G., Fuzatti, J. S., Oliveira, C. R., Campos, L. A., et al. (2017). Association between carotid intima media thickness and heart rate variability in adults at increased cardiovascular risk. Front. Physiol. 8:248. doi: 10.3389/fphys.2017.00248

Raghuraman, N., and Cahill, A. G. (2017). Update on fetal monitoring: overview of approaches and management of category II tracings. Obstet. Gynecol. Clin. North Am. 44, 615-624. doi: 10.1016/j.ogc.2017.08.007

Ross, M. G., and Gala, R. (2002). Use of umbilical artery base excess: algorithm for the timing of hypoxic injury. Am. J. Obstet. Gynecol. 187, 1-9. doi: 10.1067/mob. 2002.123204

Santo, S., Ayres-De-Campos, D., Costa-Santos, C., Schnettler, W., Ugwumadu, A., Da Graca, L. M., et al. (2017). Agreement and accuracy using the FIGO, ACOG and NICE cardiotocography interpretation guidelines. Acta Obstet. Gynecol. Scand. 96, 166-175. doi: 10.1111/aogs.13064

Silberstein, T., Sheiner, E., Salem, S. Y., Hamou, B., Aricha, B., Baumfeld, Y., et al. (2017). Fetal heart rate monitoring category 3 during the 2nd stage of labor is an independent predictor of fetal acidosis. J. Matern. Fetal Neonatal Med. 30, 257-260. doi: 10.3109/14767058.2016.1172064

Stout, M. J., and Cahill, A. G. (2011). Electronic fetal monitoring: past, present, and future. Clin. Perinatol. 38, 127-142. doi: 10.1016/j.clp.2010. 12.002

van Scheepen, J. A., Koster, M. P., Vasak, B., Redman, C., Franx, A., and Georgieva, A. (2016). Effect of signal acquisition method on the fetal heart rate analysis with phase rectified signal averaging. Physiol. Meas. 37, 2245-2259. doi: 10.1088/1361-6579/37/12/2245

Westerhuis, M. E., Schuit, E., Kwee, A., Zuithoff, N. P., Groenwold, R. H., Van Den Akker, E. S., et al. (2012). Prediction of neonatal metabolic acidosis in women with a singleton term pregnancy in cephalic presentation. Am. J. Perinatol. 29, 167-174. doi: 10.1055/s-0031-1284226

Conflict of Interest Statement: The authors declare that the research was conducted in the absence of any commercial or financial relationships that could be construed as a potential conflict of interest.

Copyright $\odot 2018$ Medeiros, Dobre, da Silva, Brateanu, Baltatu and Campos. This is an open-access article distributed under the terms of the Creative Commons Attribution License (CC BY). The use, distribution or reproduction in other forums is permitted, provided the original author(s) and the copyright owner(s) are credited and that the original publication in this journal is cited, in accordance with accepted academic practice. No use, distribution or reproduction is permitted which does not comply with these terms. 